\title{
Editorial: Child-Animal Relations and Care as Critique
}

\author{
Tuure Tammi, Riikka Hohti, and Pauliina Rautio, Guest Editors
}

\section{Multispecies relationships}

Animals and children are a classic combination since the days of Rousseau, based on the assumed natural and innocent qualities, the need of protection, and the lack of reason associated with both categories (Taylor, 2011). Affrica Taylor, for one, has traced this romanticized grouping to the persistent and characteristic nature/culture binary of Western thinking. The vast majority of the studies made on children and animals have not disrupted this binary or the hierarchies that are produced with it, and research settings have mostly remained instrumental-it has been other animals' role as facilitators or catalysts for children's development or skills that has been seen as interesting.

Childhood scholars have for some time worked toward the idea that instead of being situated in their own micro worlds, waiting rooms, or margins, children should be viewed and accounted for as full participants of society. This special issue aligns with this aspiration, while broadening the notion of what counts as society. It asks how to live and care in a society that does not consist of adult human individuals only, but instead counts children and other-than-human animals in the realm of the social and the societal. By inviting authors to think about child-animal relations and care, we wish to shed light on the ways in which other animals are relevant for human children's lives, and vice versa, and to argue for the importance of these relations for society in the conflicting times we live in now.
Multispecies relationships can be seen as a sidelined topic in the study of childhood, but at the moment this is changing. For example, the so-called childhoodnature research (Cutter-McKenzieKnowles et al., 2020) and scholars belonging to the Common Worlds Research Collective (https:// commonworlds.net/ ) look at childhoods lived at the intersections of bodies in the large frame of "more-than-human" world. This research often takes theoretical influence from Donna Haraway, whose concept of natureculture-referring to the unfolding of nature/culture dichotomy-allows for studying children as relational becomings together with other humans and animals, rather than accounting for children's activity against a certain environment or background.

This issue on child-animal relations aims to contribute to the "animal turn" that is beginning to take place in the fields of childhood studies and education. With Pedersen and Pini (2017) we acknowledge the assertive theoretical and methodological provocation this turn entails. In their special issue on more-than-human epistemologies, it was suggested that the more-than-human paradigm has, in many cases, been taken up too lightly and too quickly, leaving the profound consequences of the ontology intact. We are proud to deliver this issue with a collection of articles that both seek to go beyond the generalized categories of "child" and "animal" and do not take lightly the methodological challenges of a morethan-human paradigm.

The articles of this issue offer a set of fresh approaches: intra-active analysis of agential cuts (Aslanian \& Rigmor Moxnes); historically conscious analysis of child-horse relationships (Mukherjee); witnessing as a relational research practice (Drew \& McAlpine); storying as part of a caring assemblage (Molloy Murphy); response-ability as an intra-active encounter in the field (Ejlertsen); slowing down and strangeness as a way of troubling categories 
of childhood/nature/culture (Mulvenna); and touch as a way of knowing and making worlds (Tammi \& Hohti). In various ways, all of these approaches impose an ontological engagement or entanglement where the researcher subject "recasts herself as sensibility" (Mulvenna, this issue).

\section{Care as critique}

According to Joan Tronto's (2010) broad definition, care is "everything that we do to maintain, continue and repair 'our world' so that we can live in it as well as possible" (p. 160, italics added). The authors of this special issue engage in various explorations of what this "we" and "our world" involves, suggesting that a relational notion of care can disturb the anthropocentric thought systems that have long framed our understanding. Thinking about how other animals participate in and do care work, for instance, is important considering that many animals are now facilitated as therapeutic and pedagogical animals in a range of children's spaces (see e.g., Mukherjee in this issue).

This collection of articles suggests that care can help us to explore the complexities of lived relations-situated assemblages of different scales of vital yet noninnocent world making. Care is not a promise of a "happy ending" (Molloy Murphy, this issue) because, as Maria Puig de la Bellacasa (2017) suggests, care is ultimately about thick and impure involvement in the world. Care is thus active world making that still insists on the uncertain ethics of "as well as possible." Care as a research practice means giving specific attention to those situations in which the question of how to care is persistent but not easily answerable. The impetus of not knowing-a lack of solutions that could establish final peace-but acknowledging the need to respond anyway is well present in the articles of this selection.

But why think about care in connection with children and animals? After an era of intense theoretical development in the field of childhood studies, we find that there is currently a moment of frustration in reviewing what can be accomplished by material and relational theorization. The topic of this issue is our effort to surpass the general reaffirming of relationality and interdependence and to take at least one tiny step toward what might come after (Kraftl, 2020). Recent feminist perspectives, such as those offered by Tronto (2010) and Puig de la Bellacasa (2017), have shown us that care is a topic worth serious thought in today's world, but also, and perhaps more crucially, a tool for doing situated critique within the frame of relational ontology. And importantly, care is not necessarily associated with warm affects or good intentions: Caring can also be burdensome, undervalued, even coercive (Murphy, 2015), and practices of care can be seen as ultimately uncertain and impure-in all, "noninnocent" (Puig de la Bellacasa, 2017).

Talking about research interests as "matters of care" allows us to embrace the simultaneous dimensions of feelingsfondness, worry, trouble, concern (Murphy, 2015) — and work. In addition, care shapes research beyond the choice of topical interest, gesturing to a close examination of the affective, material, and ethical/political dimensions of particular situations, dimensions which can also be in tension with each other (Puig de la Bellacasa, 2017). The materiality of care emphasizes the hands-on work that living in relations involves. In connection with other-thanhuman animals, engaging with care in research can help us broaden our conceptions of knowing to encompass not knowing, as well as approaches such as nonverbal "attuning" (Despret, 2016) and "passionate immersion" in multispecies relations (van Dooren et al., 2016). Ultimately, care provides a mode of critique that might matter more than ever amid the complexities we live in right now-the multiple overlapping environmental crises of mass extinction, deforestation, and (at the time of writing this editorial) the COVID-19 pandemic. This critique is neither critical in a corrosive fashion nor naive in its optimism but primarily constructive and affirmative. It offers a way to disturb our sense of comfort and accomplishment in a way that does not paralyze, helping us to "stay with 
the trouble" (Haraway, 2016) while not losing the "horizon of hope" (Braidotti, 2013).

One of the political and ethical dimensions that come under scrutiny with the notion of care as critique is the commercial assemblages that turn animals into commodities and resources for human use. While animals have always been present in children's lives, today's urbanization and industrialization have diminished the variety of such encounters (Rautio, Tammi, \& Hohti, forthcoming). At the same time, societies have made themselves dependent on industrial farming, and the pet industry is growing. Indeed, the dominant strand within the study of child-animal relations reports on the positive effects that pets have on children's socio-emotional skills and wellbeing (Daly \& Morton, 2003; Jacobs Bao \& Schreer, 2016; Vidovic et al., 1999). The anthropocentric hierarchization of species is noninnocently entangled in these "affective economies" (Ahmed, 2004) and assemblages of biopower, highlighting the importance of a deeper examination of the productions and practices of care. Those animals not fit for the human temporalities and spaces of care become dropouts of the companion animal industry complex-"rescue" animals (if not euthanized). The conclusion is an acknowledgement of the inherent and difficult complexity of child-animal relations. While emotionally rewarding, characterized with love and proximity, and often significant for the children and nonhuman animals involved, most child-animal relations in contemporary societies are situated on a continuum of what Thom van Dooren (2014) calls "violent-care."

\section{Troubles full of wonder}

The seven articles included in this issue contribute to the growing archive of multispecies stories of children's worlds. While activating the speculative potentials of storytelling (e.g., Haraway, 2016) that effort to broaden the existing and dominant vocabularies and imagination, these stories are not told without hesitation and uncertainty concerning the possibility to tell about other animals' worlds. Thus, speculative storytelling is regarded as a practice of care itself, given that stories need work to endure long enough to be told and retold; they involve affects and produce versions of bodies while drawing connections and boundaries between them. Adapting Haraway's (2016) thinking, it matters what stories we tell stories with. For example, Amy Mulvenna (this issue) explores the ways responsibility and accountability are embedded in our storytelling practices; she encourages us to tell stories that think with "the liveliness of our own more-than-human world that is so full of wonder."

The special issue is opened by an "ideas from practice" entry by Angela Molloy Murphy. Situated in a homebased setting, the article grapples with the question "When our care for another cannot ensure them a "happy ending, how does our care matter?" The practices of care as well as actual lives and deaths involved in the fostering activity of the early childhood centre provoke the author to revisit the enduring question regarding the value of our care for creatures with precarious futures. A particular encounter with a piglet sparks a deeper inquiry into how environmental problems (forest fires), the sometimes-forceful practices of feeding, emergence of trust and attachment, and practices of the animal industry entangle in the material complexities of care. When the day comes to bring the pig back to the farm, there is no promise of a happy future.

In their article on touching, Tuure Tammi and Riikka Hohti draw attention to material caring practices and the ways human hands are involved in them. Focusing on how the bodies of both humans and nonhuman animals engage in practices of care and the common touching practice of stroking, they consider touch as a world-making dance in which embodied knowing and not knowing are at play. The authors argue that both humans and other animals participate in the politics of regulation and boundary making through touch. Such bodily dances are likely to involve unequal power relations-taken-for-granted human exceptionalism and superiority-however, they also remain "open and precarious, thus also allowing the disruption of these very same ideas as well as other toxic imaginaries." 
A story about both real and imaginary relations with more-than-human others unfolds in John Drew and KellyAnn MacAlpine's article on witnessing the ruins. Starting from the observation that early childhood educational approaches to care are often decontextualized from ecological and more-than-human precarities, as well as the economic influences contributing to such precarities, the authors ponder how educators and scholars might reclaim and augment the politics of care. Through storying everyday encounters with "real, shadowy, and mythical" animals of the forest and children's questions about them, they explore the possibility of crafting pedagogies that would, instead of escape, embrace the instability and precarity of everyday environments. The article works against outcome-driven and data/evidence-based approaches in early childhood education, emphasizing the value of cultivating curiosity while acknowledging the troubling productions of structural injustices between humans, other species, and landscapes that the children and the educators are embedded in.

The notion of vulnerability is central to Marija Ejlertsen's article that discusses conflicting enactments of care among the researcher-educator, children, and rescue animals in the context of a school for marginalized children. Working beyond "naturally" positive, unidirectional, and binary notions, the author argues that being exposed to the other and becoming vulnerable through this encounter could be productive for the emergence of care as it allows a shift or a move away from the commonplace positions of carer and cared for. They insist that a more-thanhuman relational lens can open possibilities of caring otherwise. Ejlertsen writes: "By being open to be affected and undone by the multiple possibilities of caring in the encounter, I experience the encounter in a new light, which offers everyone involved greater ontological possibilities to respond and be otherwise, not least myself."

Care is regarded as ontological engagement in Teresa Aslanian and Anna Rigmor Moxnes's article. They show how representations of animals, specifically the common cow figurine used in kindergarten play, entangle with both warm affects toward animals and more aggressive histories of human-cow relationships that are largely made imperceptible through displacement. Through their analysis of children's play with Holstein cow figurines as noninnocent care practices in the context of early childhood education, they explore how relations between children and animals and representations of animals can involve care, but not necessarily moral care.

The idea of displacement is also picked up by Amy Mulvenna, who offers readings with care of two children's tales by the author Shaun Tan. Mulvenna speculates on what becomes possible for the child reader of these stories of childanimal encounters, suggesting that the weirdness, surreality, and strangeness in these tales provide a possibility to depart from humancentric forms of knowing by offering an open-ended engagement and interconnectedness with the material surroundings. What emerges is a specific kind of becoming-with, one linked with slow movements and "unhurried processes of deliberation, noticing, and attending to that which is present."

Utsa Mukherjee writes about the idea of "becoming with" in his article on child-horse relationships. The discussion is based on one case in particular where the child preferred tasks of caring for the horses (mucking stables, feeding, organizing stuff) to riding the horses. Mukherjee interprets the materiality and richness of the "horse world"-the scents, sounds, practices, and habits of both horses and people caring for them-to be a world-making experience, allowing for "becoming with the horse" more than just riding a horse would. Mukherjee also stresses that the role of the horse is an active rather than a dominated one in this world making.

\section{Conclusion}

Traversing the currently popular theoretical and methodological lines of posthumanism, postqualitative inquiry, and new materialism(s) and emphasizing a relational ontology, as many child-animal scholars do, is not an innocent or straightforwardly nonanthropocentric endeavour. Peter Kraftl (2020), for one, points out things to look out for. First, the prefix "post," in his view, indicates an approach that can become enamoured with continual 
search for newness and endless going "beyond" and thus cease to be able to make a real difference in the here and now. Second, the focus on relations can blur the existence of others-things and beings-outside of their relations with humans. This can lead to effacing or erasing the other, exhausting the very being of the other to the relation in focus. Kraftl's concern is that unless critically examined and situated, studies focusing on relations and stories within the "post paradigm" can unintentionally end up reinforcing white / middle-class / European privilege.

One of the rationales for creating this special issue around the notion of care as critique has been to interrupt essentializing discourses and discuss child-animal relations as situated. An idea common to many earlier studies of children and animals is the "biophilia hypothesis" (Tipper, 2011), which claims that the "universal human instinct" to care for all life is especially strong in children (e.g., Melson, 2001). Such understandings not only essentialize children (and humans) but also idealize and romanticize care as some "wholesome or unpolluted pleasant ethical realm" (Puig de la Bellacasa, 2017, p. 8). Caution regarding essentializing the experiences of others as well as idealizing and romanticizing care is critical. Childhood and child-animal relations are important contexts for exploring the complex and far-reaching effects of care because in them the above-mentioned tendencies are continuously brought to present. It is seemingly easy to have an opinion on what constitutes good care with regard to children and other animals. Approaching care as a situated practice, however, allows for more complex analyses and staying with the joyous trouble of care.

\section{Acknowledgements}

As guest editors we thank all the contributing authors for sharing their passion and insights and for their patience during the process of refining this issue. We wish to especially thank the many committed reviewers for their invaluable feedback as the papers in this issue took form. Echoes of your voices and encouragement sound in the following pages. Wonderful Meagan Montpetit, thank you for guiding us through and keeping us abreast of the editorial process. Finally, we would like to remark that the editing of this special issue has been an equal contribution between the three guest editors, and the same goes for writing this editorial. 


\section{References}

Ahmed, S. (2004). Affective economies. Social Text, 22(2), 117-139. https://doi.org/10.1215/01642472-22-2 79-117

Braidotti, R. (2013). The posthuman. Polity Press.

Cutter-Mackenzie, A., Malone, K., \& Barratt Hacking, E. (2018). Research handbook on childhoodnature. Springer International Handbooks of Education.

Daly, B., \& Morton, L. L. (2003). Children with pets do not show higher empathy: A challenge to current views. Anthrozoös, 16(4), 298-314. https://psycnet.apa.org/doi/10.2752/089279303786992026

Despret, V. (2016). What would animals say if we asked the right questions (B. Buchanan, Trans.)? University of Minnesota Press.

Haraway, D. (2016). Staying with the trouble: Making kin in the Chthulucene. Duke University Press.

Jacobs Bao, K., \& Schreer, G. (2016). Pets and happiness: Examining the association between pet ownership and wellbeing. Anthrozoös, 29(2), 283-296. https://doi.org/10.1080/08927936.2016.1152721

Kraftl, P. (2020). After childhood: Rethinking environment, materiality and media in children's lives. Routledge.

Melson, G. (2001). Why the wild things are: Animals in the lives of children. Harvard University Press.

Murphy, M. (2015). Unsettling care: Troubling transnational itineraries of care in feminist health practices. Social Studies of Science, 1-21. https://doi.org/10.11770306312715589136

Pedersen, H., \& Pini, B. (2017). Educational epistemologies and methods in a more-than-human world. Educational Philosophy and Theory, 49(11), 1051-1054. https://doi.org/10.1080/00131857.2016.1199925

Puig de la Bellacasa, M. (2017). Matters of care: Speculative ethics in more than human worlds. University of Minnesota Press.

Rautio, P., Tammi, T., \& Hohti, R. (forthcoming). Childhood after the "animal turn": Child-animal relations and multispecies scholarship. In N. Yelland et al. (Eds), SAGE handbook of global childhoods. SAGE.

Taylor, A. (2011). Reconceptualizing the "nature" of childhood. Childhood, 18(4), 420-433. https://doi.org/10.11770907568211404951

Tipper, B. (2011). "A dog who I know quite well”: Everyday relationships between children and animals. Children's Geographies, 9(2), 145-165. https://doi.org/10.1080/14733285.2011.562378

Tronto, J. (2010). Creating caring institutions: Politics, plurality, and purpose. Ethics and Social Welfare, 4(2), 158-171. https://doi.org/1 $\underline{0.1080 / 17496535.2010 .484259}$

van Dooren T. (2014). Care. Environmental Humanities, 5(1), 291-294. https://environmentalhumanities.org/arch/vol5/5.18.pdf

van Dooren, T., Kirksey, E., \& Münster, U. (2016). Multispecies studies: Cultivating arts of attentiveness. Environmental Humanities, 8(1), 1-23. https://doi.org/10.1215/22011919-3527695

Vidovic, V. V., Stetic, V. V., \& Bratko, D. (1999). Pet ownership, type of pet, and socio-emotional development of school children. Anthrozoös, 12(4), 211-217. https://doi.org/10.2752/089279399787000129 